\title{
Modeling of Growth Kinetics of Conifer Trees
}

\author{
Alexander S. Kholmanskiy \\ Institute of Electrification of Agriculture, Moscow, Russian Federation \\ Email: allexhol@ya.ru \\ Received 5 December 2014; revised 20 December 2014; accepted 31 December 2014 \\ Copyright (C) 2015 by author and Scientific Research Publishing Inc. \\ This work is licensed under the Creative Commons Attribution International License (CC BY). \\ http://creativecommons.org/licenses/by/4.0/

(c) (i) Open Access

\begin{abstract}
The kinetics of growth of conifers is modeled by the dependence of the area of tree rings on time. The data on the growth of 46 coniferous trees varying in age from 35 to 242 years, found in the literature are analysed. To identify the common patterns in the growth kinetics, we investigate the series of standard increments of tree rings for pine, spruce, and larch. The curves obtained reflect adequately the ontogeny of trees. These allow the analysis of the environmental effects' on the physiology of trees. In such a way the accelerated growth of trees in the Tunguska meteorite explosion zone is established. The proposed method of dendrochronology based on the area of tree rings is more adequate and informative than the method based on tree-rings' widths.
\end{abstract}

\section{Keywords}

Tree-Ring Area, Growth Kinetics, Area of Tree Rings, Phytohormones, Conifer

\section{Introduction}

The growth of coniferous trees is sensitive to a wide range of physical factors. The dominant factors include sunlight, temperature and humidity of the environment. These abiotic factors determine the kinetics of growth of tree rings. Their effect on the physiology of trees forms the main subject of dendrochronology and dendroclimatology. In the reconstruction of the chronological scales for different samples the reference points are formed by the years of drought or cooling, which reveal a sharp decrease in the growth (Kolchin \& Chernih, 1977; Vaganov, 2007). Other factors, inhibiting photosynthesis and growth include air pollution due to volcanic eruptions (Vaganov, 2000).

The integral intensity of the incident light on the Earth surface varies in the range of $0.3 \%$ with a period of approximately 11 years. These variations are related to the Solar Activity (SA) in correlation with the number of sunspots (Wolf number-W). The SA influences the state of the magnetosphere and the living creatures, includ- 
ing humans (Martinyuk, 2008). However, in the dendrograms the SA rhythms are masked considerably by complex regional climate changes. Even more difficult it is to identify in the dendrograms the other physical effects, other regional/cosmic factors (Lovelius \& Kolesnikov). These include local electric and magnetic fields, geosphere chemistry, radiation of terrestrial and cosmic origin. On the other hand, in some cases the origin and the nature of the factors that lead to some obvious changes in the kinetics of growth and in wood structure are still not clear, along with the mechanisms of adaptation to it. Such phenomena include the accelerated growth of trees in the area of the Tunguska Meteorite explosion (TM) (Site TM), as well as the twisting of fibers in the wood of conifers (spirotropizm) (Kholmanskiy, 2009) and complex curving of tree trunks in some terrains.

In dendroecology the methods of statistical analysis (averaging, indexing) are used widely in the studies of various factors' impact upon the growth of wood in time, of the corresponding mechanisms and chronology (Lovelius \& Kolesnikov; Lovelius \& Lezneva). These methods are justified in the construction of absolute dendrochronological regional scales. However, the smoothing of the curves of annual increments by methods of indexing and statistical averaging leads to losses. Thus, the information about the effects on tree physiology of the factors that have time-periods of the order of the averaging intervals (10 years), and even more the aperiodic ones gets lost. In whole, the frequency/amplitude parameters of various dendrochronologies, derived with the use of the statistical processing vary in very wide ranges, making the identification of any patterns very problematic (Demakov).

In this paper, we study the growth kinetics on the basis of the data on tree physiology, using as the basic parameter the tree ring area instead of its width. In order to identify the common patterns of growth we analyze the data on series of standard increments of tree rings for conifers (pine, spruce, larch). For an illustration of the sensitivity of the method to physical factors, we studied the dynamics of the growth of trees in the area of the TM explosion with the help of the photographs of cross-section cuts for young trees and for those that survived the explosion.

\section{Materials and Methods}

\subsection{Presentation of the Study Area}

The data on the annual growth of trees we acquire from the literature. We use as examples

- 15 pine and 23 spruce trees (Lovelius \& Kolesnikov) in the country side of Zeleso Luga district, Leningrad region (58 $56^{\prime}$ north latitude $29^{\circ} 48^{\prime}$ east longitude);

- spruce in fir-wood and in bilberries forest (Lovelius \& Lezneva), Vologda region ( 61 $40^{\prime}$ north latitude $\sim 37^{\circ} 36^{\prime}$ east longitude);

- 242-Year-old larch (Lovelius, 2011), East Taimyr, river basin Novaya (72³0' north latitude);

- cuts of trees from the Tunguska explosion zone (Figure 1) in the area of the Podkamennaya Tunguska River (605' north latitude $101^{\circ} 57^{\prime}$ east longitude).

\subsection{Mathematical Model of Growth}

The annual growth of wood biomass can be specified by the formula:

$$
M_{i}=\langle\rho\rangle h S_{i}=\langle\rho\rangle 2 \pi h R_{i} d_{i}
$$

Here $\langle\rho\rangle$ is the average density of wood, $S_{i}$ is the area of $i$-th ring of radius $R_{i}, h$ and $d_{i}$ are the height and the width of the $i$-th annual ring. The values of $R_{i}$ for the cross-sections of young trees and of the reference trees with known dendrochronology we calculated through the formula:

$$
R_{i}=\sum_{l}^{i} d_{i}
$$

Values of $d_{j}$ we obtained from the tables provided in the papers (Lovelius \& Kolesnikov; Lovelius \& Lezneva; Lovelius, 2011).

For the trees-survivors of the TM explosion we used the formula:

$$
R_{i}=R_{0}+\sum_{l}^{i} d_{i}
$$




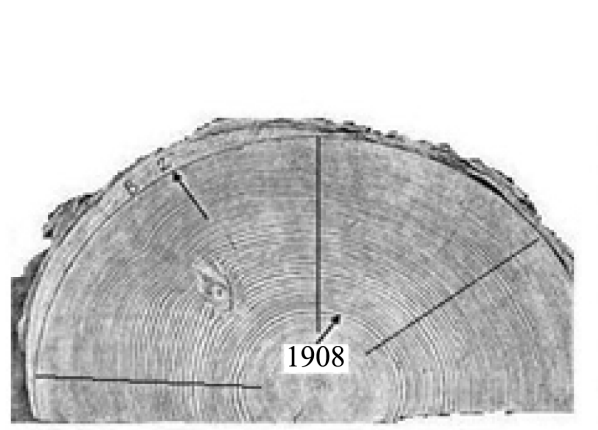

(a)

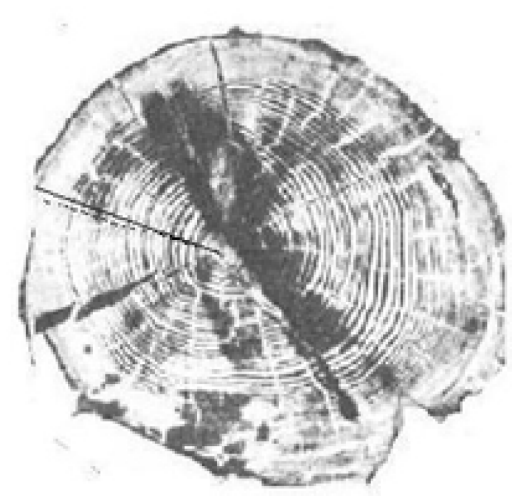

(d)

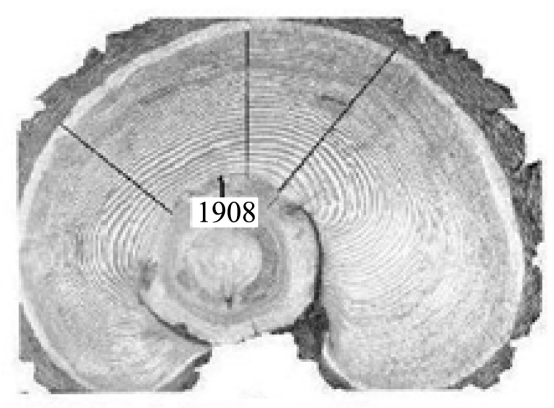

(b)

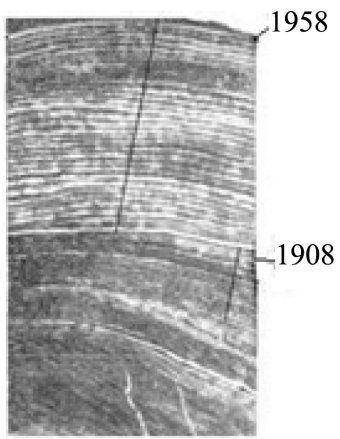

(c)

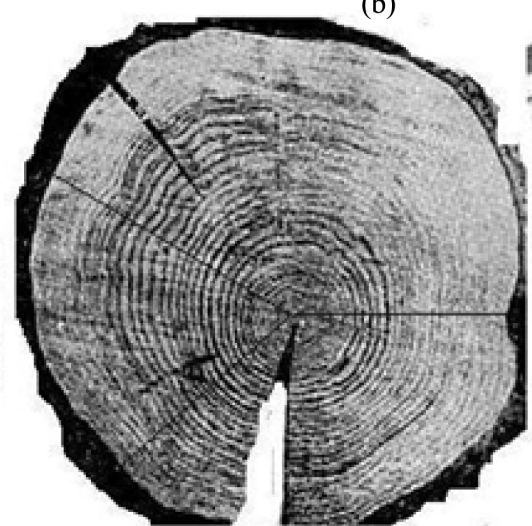

(e)

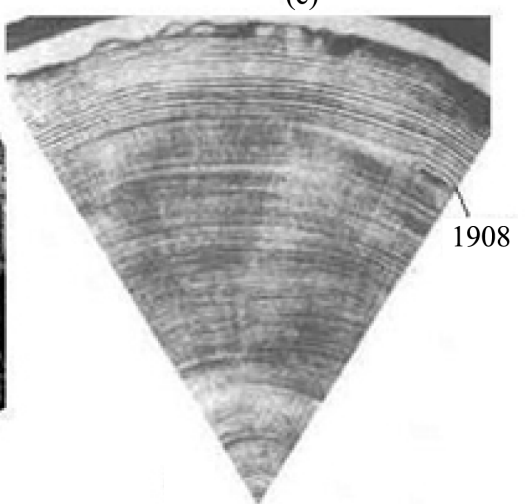

(f)

Figure 1. Cuts of trees from the Tunguska explosion zone (Site TM). (a) is for spruce-Longo, the rest are for larches; (b) 180-; (c) 290-; (d) 35-; (e) 47-; (f) 227-year-old. Lines show the directions for dendrochronology calculations.

In Equation (2) $R_{o}$ is the radius of the annual ring that precedes the TM explosion (Figures 1(a)-(c)). The value of $h$ is proportional to the average length of the tracheids. Assuming $\left\langle\rho>\right.$ weakly dependent on $R_{i}$, we find the proportionality $M_{i} \sim S_{i} \sim R_{i} d_{i}$, where $R_{i}$ is calculated by the Formula (1) or (2) depending on the wood. The values of $R_{o}$ and $d_{j}$ were measured from the photographs of the cuts along several radii with the use of the program Adobe Photoshop.

The reference point for trees' dendrochronology from the TM blast zone is year 1908. After that the survivor trees grew faster significantly. As most of the photos of tree cuts had no length scale, we used the average values of growth increments from reference series to set the scales. The digitization of ring growth increments, the calculation of the corresponding areas, and curve plotting were performed with the use of Adobe Photoshop and Microsoft Office Excel.

\section{Results}

Photos of cuts of trees from the Tunguska explosion zone (Site TM) shown in Figure 1. The comparative dendrograms of the changes of metric parameters for different trees are presented in Figures 2-4.

\section{Discussion}

\subsection{Aanalyses of the Forms of Dendrograms}

Figure 5 demonstrates a typical growth curve that reflects the physiological stages of the development of a tree. Comparison of this curve to the dendrograms in Figures 2-4 shows that the increments of the area of tree rings reflect adequately the ontogeny and phylogeny of trees, in contrast to the dendrograms of radii increments.

This may serve as a justification of the method of comparative analysis of the kinetics of biomass growth $(\sim S)$ in standard and abnormal conditions. An example of such a comparison is provided by the dendrograms in Figure 4. This comparison reveals the fact that the growth of trees in the area of the TM explosion was catalyzed by 


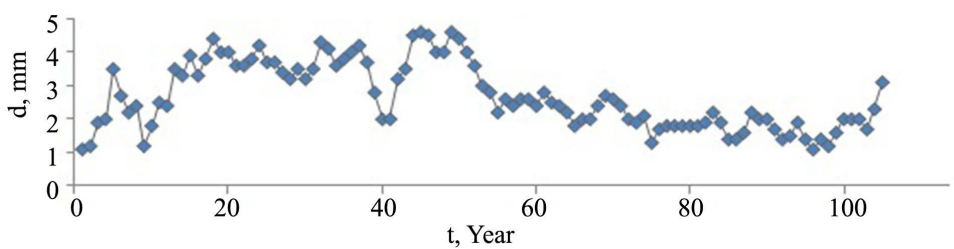

(a)

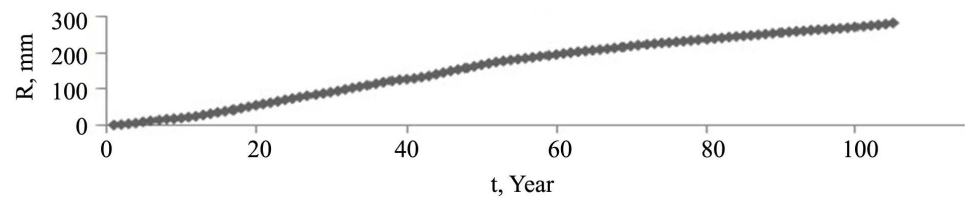

(b)

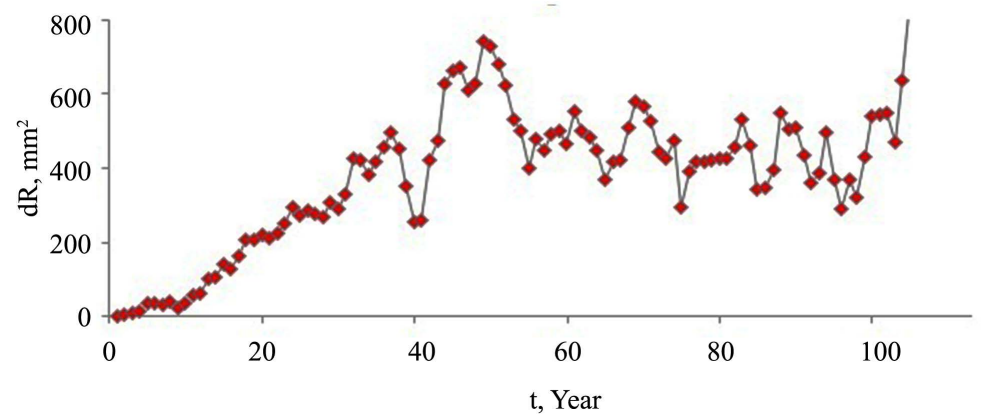

(c)

Figure 2. Comparative dendrograms for a pine-tree: width of tree rings (d), average for 15 trees (Lovelius \& Kolesnikov); radii of rings (R), calculated with Equation (1); area of pine tree rings (dR).

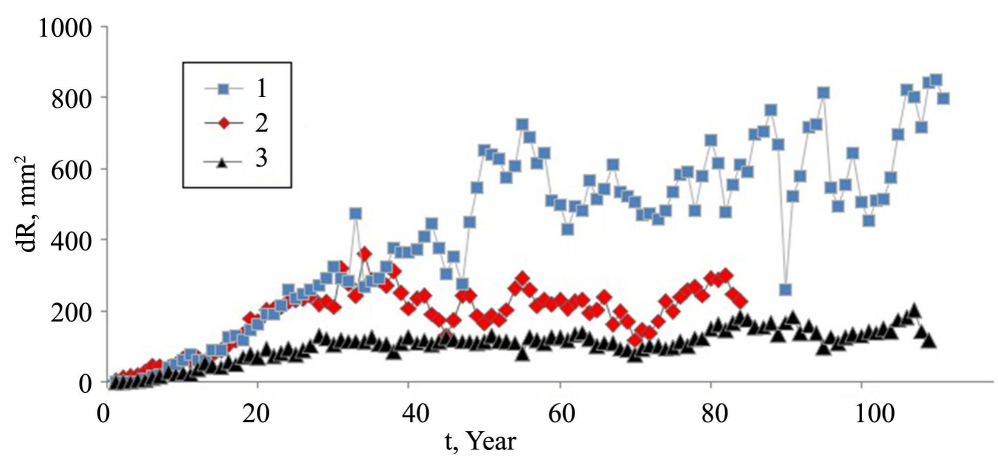

(a)

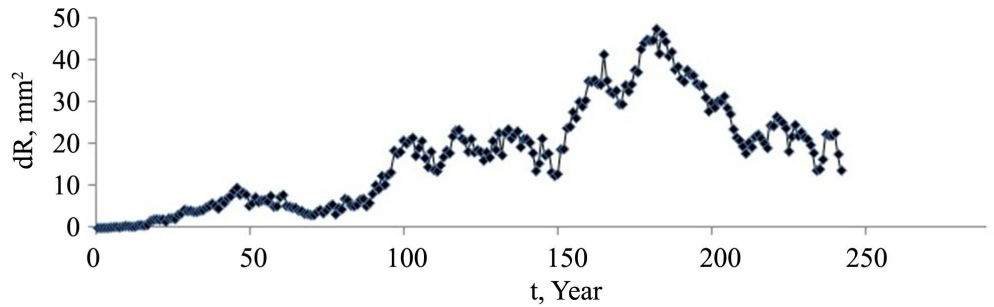

(b)

Figure 3. Dendrograms of the increments of tree-ring area for spruce (a): 1 - average values of $\mathrm{d}$ for 23 trees (Lovelius \& Kolesnikov); 2-spruce in fir-wood (Lovelius \& Lezneva); 3-spruce in bilberries forest (Lovelius \& Lezneva); and 242-year-old larch (b) (Lovelius, 2011). 


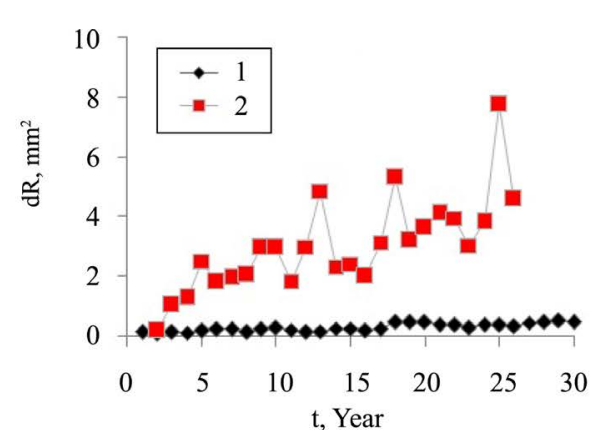

(a)

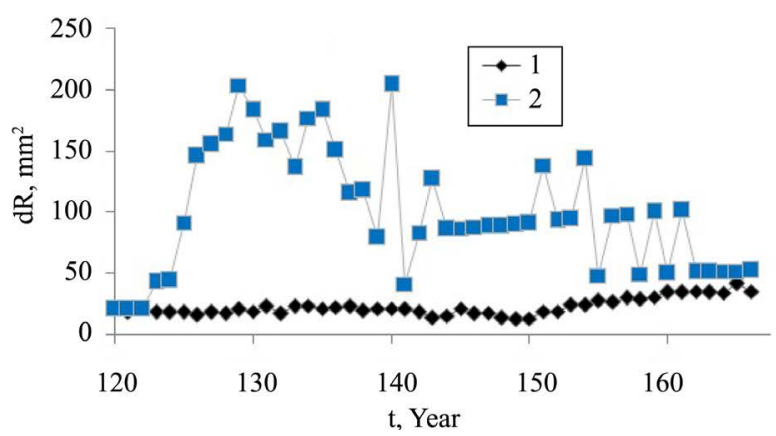

(b)

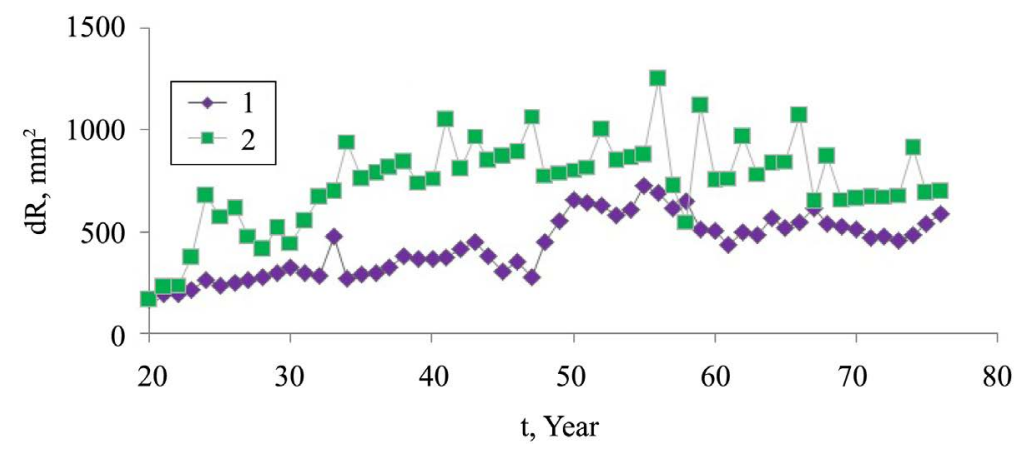

(c)

Figure 4. Comparison of dendrograms of increments of tree-ring areas for reference trees (1) with those from the Tunguska explosion region (2,3). Plot (a) is for larch: 1-242-; 2-35-year-old. Plot (b) is for larch: 1-242-; 2-180-year-old. Plot (c) is for spruce: 1 - average values of $\mathrm{d}$ for 23 trees; 2 -spruce-Longo (Site TM).

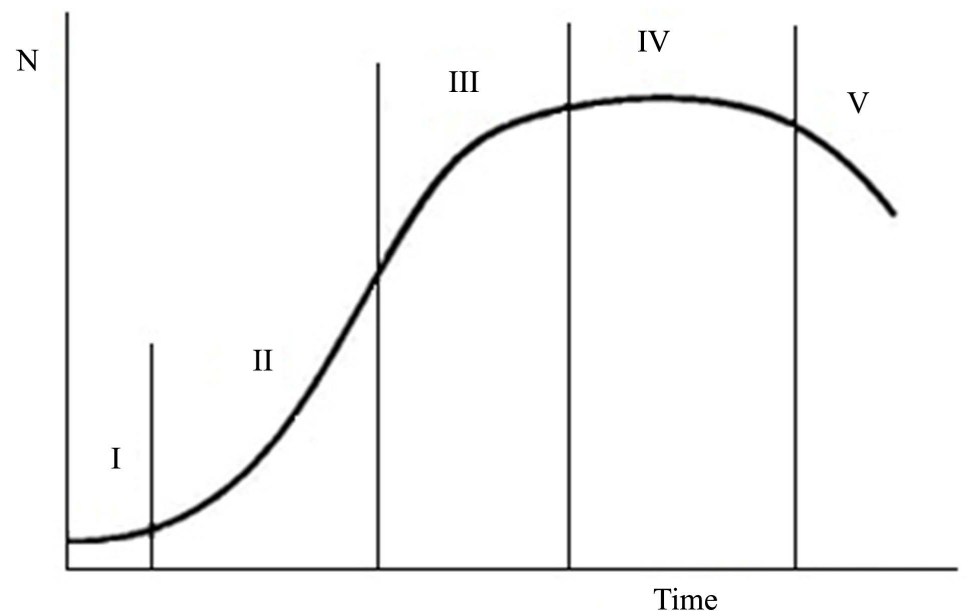

Figure 5. The growth curve of the plant, with N-the number of cells: I-lag phase, seed adaptation and initial sprouts; II-exponential phase of leaves' and roots' biomass growth; III-fruiting (breeding) phase; IV—stationary phase; V-degradation phase (Alechina, 2005).

some factor, the effect of which fades in 50 years after the TM explosion. This time period embraces the I - III physiological stages of young trees' growth or IV - V physiological stages of TM explosion survivor trees.

\subsection{Physico-Chemical Analyses of the Trophic Function of Merisystem}

The adaptation of trees to the action of external factors is related to the changes in the trophic function of merisystem. This function is based on the following physico-chemical processes: 
A - exchange of energy and matter with the external environment,

$\mathrm{B}$ - transportation of products of photosynthesis and nutrients through the tree structure,

C-intracellular metabolic reactions, providing growth and reproduction.

The kinetics and energetics of all the three processes rest upon the molecular and electrophysical properties of water (Kholmanskiy, 2013; Medvedev, 2012). The cellular metabolism (C-process) is limited by the B-process, which changes in the ontogeny and is more sensitive to the changes of the external factors than the A- and Cprocesses. As the water content of the conifer tissues is about $70 \%$ on average, they can be represented by a simple singly-connected heterogeneous electrolytic system (Kholmanskiy, 2013). The content of mineral salts in the xylem sap is by one or two orders of magnitude higher than that in the soil. The key role in the mechanism of its movement is provided by potassium ions (Alechina, 2005).

\subsection{The Probable Mechanism of Adaptation of Trees}

The key element of the cellular trophicity is its hormonal component. It is well-studied on the example of auxin-indoleacetic acid (IAA) (Alechina, 2005; Medvedev, 2012). Auxin is synthesized in the leaves and is transported through the phloem with sucrose to all the points of growth down to those in the root system. IAA stimulates the hydrolysis of energy-rich molecules, the process of respiration, reduplication, elongation and differentiation of cells. Within the cell the IAA dissociates and launches the process of release of protons into the cytoplasm (up to $10^{4} \mathrm{H}^{+}$per one IAA molecule) (Medvedev, 2012). It also adjusts the permeability of the membrane $\mathrm{Ca}^{2+}$ channels. As a result, the proton potential of the membrane increases along with its permeability to water, sucrose and other metabolites (attraction effect). The trans-membrane transport of auxin is provided by protein-carriers. The distribution of the latter in the membrane and their efficiency are normally controlled by the genetic program. The polarization of the membrane and the intracellular dynamics of the metabolites in external fields (gravitational or electric) affect the activity of IAA (Medvedev, 2012). That leads to an increase/decrease of the attraction effect and can change its localization on the cell membrane. Thus, geotropizm and various deviations in the morphology and ontology of trees are realized under significant changes of the environment.

It is obvious that the explosion TM and subsequent a fire initiated a significant change environmental factors as well as the composition and electrophysics, soil and atmosphere (Site, TM, Kolesnikov, 1982, Kholmanskiy, 2009). After the explosion habitat relax to its original condition within 50 years. It can be assumed that these changes in environmental factors influence the kinetics of A-, B- and C-processes that led to the accelerated growth of the trees in the area of the explosion TM (Figure 1 \& Figure 3 ).

\section{Conclusion}

In the present work, we provide the dendrochronological analysis of the growth of 46 coniferous trees (pine, spruce, larch). These are growing in north latitudes from $\sim 30^{\circ}$ to $\sim 100^{\circ}$ east longitude, and their age ranges from 35 to 242 years. The kinetics of their growth was modeled by the dependence of the area of their annual rings on time. The kinetic curves obtained reflect adequately the ontogeny of trees and allow the proper explanation of the tree physiology dependence on external conditions and on age. The method of dendrochronology, proposed in this article is physiologically adequate and, we believe, more informative than the method based on tree-rings' widths.

\section{Acknowledgements}

The author is grateful to Professor N.V. Lovelius for his interest and helpful comments.

\section{References}

Alechina, N. D., Baliokin, Yu. V., Gavrilenko, V. F. et al. (2005). Plant Physiology: Textbook for Students. Akademiya, 640 p.

Demakov, Yu. P. Factors Affecting the Dynamics of the Annual Tree Growth.

http://www.volgatech.net/upload/documents/Demakov.pdf

http://www.kscnet.ru/ivs/bibl/sotrudn/firstov/fir ch r 16.pdf

Kholmanskiy, A. S. (2009). Adaptation of Trees to Abnormal Physical Factors. Mathematical Morphology. Electronic Mathematical and Biomedical Journal, 8. http://sgma.alpha-design.ru/MMORPH/N-23-html/holmanskiy/holmanskiy.htm

Kholmanskiy, A. S., Tilov, A. Z., \& Sorokina, E. Yu. (2013). Drying Kinetics of Plant Products: Dependence on Chemical 
Composition. Journal of Food Engineering, 117, 378-382.

Kolchin, B. A., \& Chernih, N. B. (1977). Dendrochronology of Eastern Europe. http://hbar.phys.msu.ru/gorm/dating/kolchin.htm

Kolesnikov, E. M. (1982). Isotopic Anomalies of H and C in the Peat from the Crash Site of the Tunguska Meteorite. Dokladi AN SSSR, 266, 993-995.

Lovelius, N. V., \& Kolesnikov A. P. Influence of Environmental Factors on the Variability of Growth of Woody Plants (Examples of Pine and Spruce in the Valley of River LUGA). http://rus.neicon.ru:8080/xmlui/bitstream/handle/123456789/6220/5_10_02_40.pdf?sequence=1

Lovelius, N. V., \& Lezneva, C. V. On the Creation of the Reference Series of Tree Rings Growth in the Vologda Region. http://pskgu.ru/projects/pgu/storage/prj/prj_16/prj_16_12.pdf

Lovelius, N. V., \& Reteyum, A. Yu. (2011). Fluctuations in the Growth of Larch in the Woodlands of Northern Taiga and in the Far-Northern Forest-Island “Ary-Mas”. Obchestvo. Sreda. Razvitie (Terra Humana), 1. http://cyberleninka.ru/article/n/kolebaniya-rosta-listvennitsy-v-redkolesie-severnoy-taygi-i-v-samom-severnom-lesnom-os trove-ary-mas

Martinyuk, V. S., Temurtyanc, N. A., \& Vladimirskiy, B. M. (2008). No Bad Weather: Cosmic Weather in Our Lives. Kiev, 212 p. http://cb.science-center.net/Files/Maket\%20B5\%20Final\%20180\%20pages.pdf

Medvedev, S. S. (2012). Electrophysiology of Plants.

http://www.bio.spbu.ru/materials/molbio/Medvedev-Electrophysiology.pdf

Site, TM. http://tunguska.tsc.ru

Vaganov, E. A., \& Kruglov, V. B. (2007). Ecology of Wood Plants. Krasnoyarsk. http://library.krasu.ru/ft/ft/_umkd/317/u_lectures.pdf

Vaganov, E. A., Briffa, K. A., Naurzbaev, M. M. et al. (2000). Long-Term Climate Changes in the Arctic Region of the Northern Hemisphere. Dokladi AN RF, 375, 103-106. 
Scientific Research Publishing (SCIRP) is one of the largest Open Access journal publishers. It is currently publishing more than 200 open access, online, peer-reviewed journals covering a wide range of academic disciplines. SCIRP serves the worldwide academic communities and contributes to the progress and application of science with its publication.

Other selected journals from SCIRP are listed as below. Submit your manuscript to us via either submit@scirp.org or Online Submission Portal.
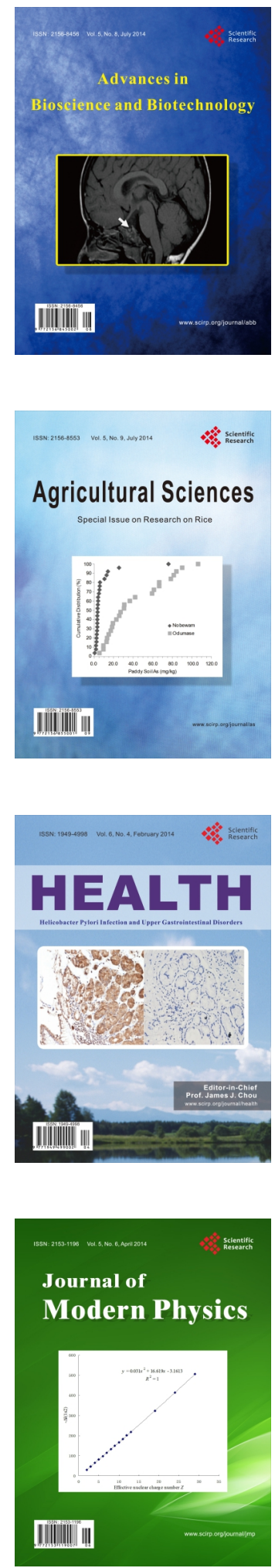
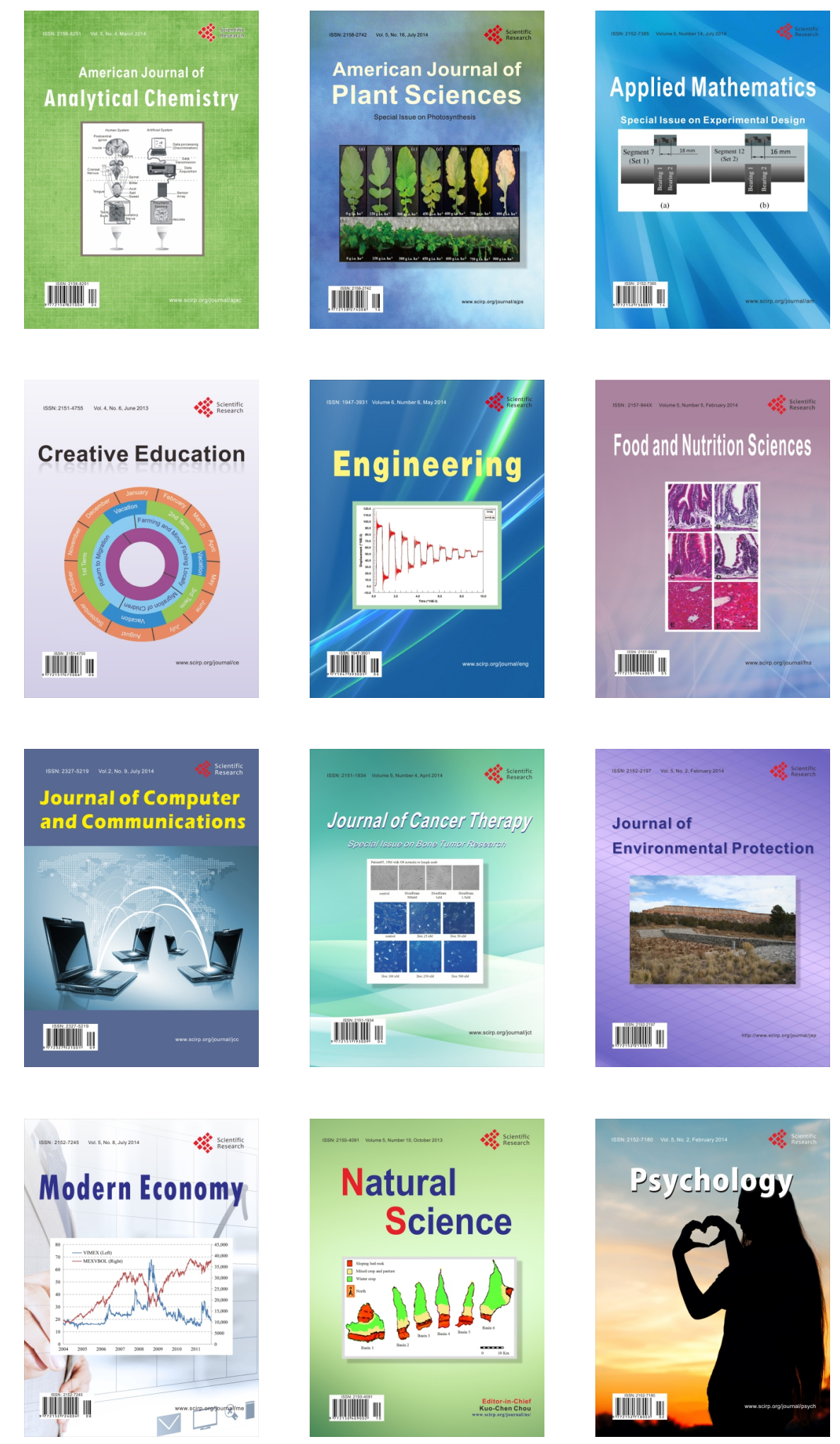